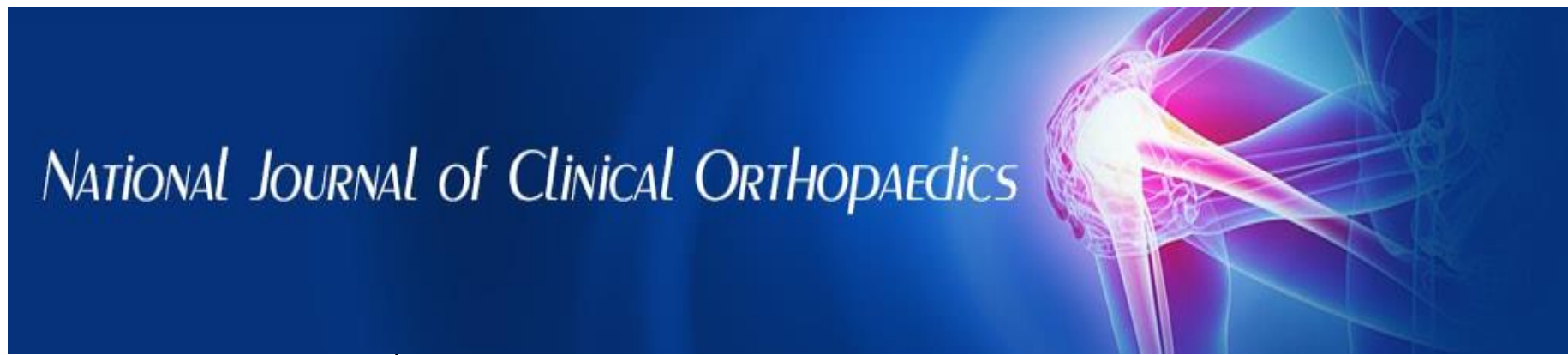

ISSN (P): 2521-3466

ISSN (E): 2521-3474

(C) Clinical Orthopaedics

www.orthoresearchjournal.com

2019; 3(1): 19-21

Received: 07-11-2018

Accepted: 11-12-2018

Dr. Mahesh Kumar NB

Associate Professor, Department of Orthopaedics, Rajarajeshwari Medical College, Bangalore,

Karnataka, India

Dr. Ullas Mahesh

Assistant Professor, Department of Orthopaedics, Rajarajeshwari Medical College, Bangalore,

Karnataka, India
Correspondence

Dr. Ullas Mahesh

Assistant Professor, Department of Orthopaedics, Rajarajeshwari Medical College, Bangalore,

Karnataka, India

\section{Comparative study of clinical outcome in the management of open vs closed tibial shaft fractures with intramedullary interlocking nailing technique}

\author{
Dr. Mahesh Kumar NB and Dr. Ullas Mahesh
}

DOI: https://doi.org/10.33545/orthor.2019.v3.i1a.06

\begin{abstract}
Introduction: Incidence of tibial diaphyseal fractures (26 per 100,000 persons per year in an average population) is the highest among long bone fractures. The present study has been taken to review the results of diaphyseal fractures of tibia, both closed \& open, treated with IMLIN.

Result: Tibial fractures were more commonly seen in males, 30-55 years constituted majority of thr fractures, dominant side was commonly involved.

Conclusion: Closed Tibial fractures have better union rates \& lesser the complications when compared to open tibial fractures which are treated with intramedullary interlocking technique.
\end{abstract}

Keywords: Tibia, Fracture, IMILN, closed, open

\section{Introduction}

The tibia by its location is exposed to frequent injuries as one third of its surface is subcutaneous. Treatment of tibial fracture in adult is a challenge to Orthopedic surgeons due to poor soft tissue coverage and blood supply. Moreover compartment syndrome, neurovascular injury and infection might add to this burden. Later non union, delayed union and malunion may include.

The acceptable treatment goal for fracture tibia is union maintaining normal length, normal alignment without rotation, deformity, normal joint movement and reduced hospital stay. About 40 years ago charnley (1961) said, "we have still a long way to go before the best method of treating a fracture of the shaft of tibia can be stated with finality".1 Intramedullary nail (Lottes, Ender) has been used for a long time for fixation of tibia.

Thus even today, the treatment of unstable shaft fracture of tibia is difficult. Various treatment modalities are used in the management of this fracture which include conservative management with cast and functional bracing to Intramedullary fixation, plating and external fixation. Locked intramedullary nailing is currently the preferred method for surgical treatment of tibial diaphyseal fracture. It provides more stable fixation and prevents rotation. Other advantages of intramedullary nailing includes closed fixation, good alignment without periosteal stripping, early ambulation and load sharing. It may be done with or without reaming. The method needs specific instruments and facilities like image intensifier and a complete set of nails, screws, and insertion devices.

As there are variations in treatment of tibial fracture, it is very difficult to manage all the cases by a single treatment method. Over last 50 years the management of tibial fracture has oscillated like a pendulum of a clock from non surgical treatment to surgical treatment. In the past, tibial shaft fracture were managed by immobilization in a plaster cast. 3 Thereafter functional brace has been used commonly. 4 The first use of an intramedullary rod is attributed by lambott in 1907. 5 In 1974 a semi-rigid triflange intramedullary nail is introduced for closed nailing in tibia without reaming. 6 But problems remain with comminuted fractures and the nail does not provide rotational stability and normal length. In 1960s and 1970s external fixation was most popular. 7 The plating resulted in higher incidence of non Union, infection and fixation failure.8 The external fixation resulted in pintract infection and sometimes osteomyelitis of bone. 9 Due to these problems a new technique close tibial interlock nailing was developed that minimize the chances of post operative infection, 10 promotes early union, regain early activity 11 and reduce exposure and operative trauma. 
Aims \& Objectives

1. To assess the clinical and radiological outcome of the patients

2. To assess the functional recovery of the patients.

3. To evaluate results of IMILN in diaphyseal fractures of Tibia, in both open \& closed types.

4. To assess the complications associated with Interlocking intramedullary nails for open tibial shaft fractures.

5. To study Rom, at knee \& ankle joints, union, non union rates \& complications associated with each technique.

\section{Materials \& Methods}

A prospective study of 100 patients, conducted in Bangalore. Study duration was 2 yrs.

\section{Inclusion criteria}

1. Closed diaphyseal fractures of tibia

2. Age groups of $18-65$ years

3. Open fractures of tibia, till type I \& type II according to Gustilo- Anderson classification.

4. All types of diaphyseal fractures excluding intrarticular fractures.

5. Fresh Tibial fractures

\section{Exclusion criteria}

1. Diaphyseal tibial fractures including intrarticular extensions.

2. Open diapyseal tibial fractures of tibia Type III A, B \& C

3. Patients coming for re surgery

4. Mal union

5. Presence of narrow medullar canal

6. Pathological fracture

\section{Result}

A prospective study of 100 patients, conducted in Bangalore. Study duration was 2 yrs. 50 Patients had closed tibial fractures $\& 50$ pts had open tibial fractures.

Below are distribution in closed tibial, open tibial Type I, Type II \& Total pts respectively.

Table 1: Total number of patients were 100, in that Males were 43 in closed type of Tibial fractures \& 45 in Type I \& type II type of open fractures $\&$ in Females 8 were from Type I Tibial fractures $\& 4$ from Type I \& Type II open fractures. These are represented in Fig 1

\begin{tabular}{|c|c|c|c|c|c|c|}
\hline Gender & No of PTS & \% & No of PTS & \% & No of PTS & \% \\
\hline Male & 43 & 43 & 45 & 45 & 88 & 88 \\
\hline Female & 8 & 8 & 4 & 4 & 12 & 12 \\
\hline Total & 51 & 51 & 49 & 49 & 100 & 100 \\
\hline
\end{tabular}

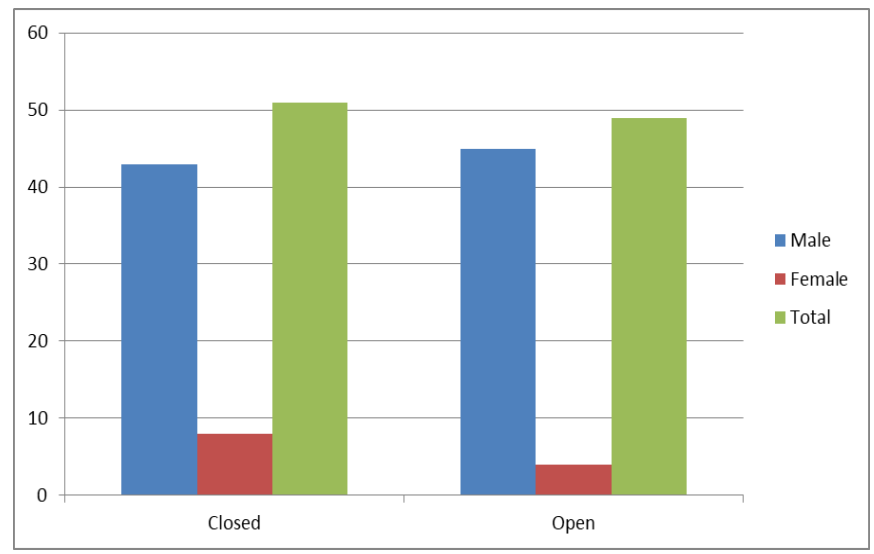

Fig 1
Table 2: Complications were minimal, few of them were, Knee stiffness 12 , Infection 8 , and no complication in 80 , same percen depicted as in Percentage in the $2^{\text {nd }}$ table $\&$ graph chart has been depicted in Fig 2

\begin{tabular}{|c|c|c|}
\hline Complications & Frequency & Percent \\
\hline Knee Stiffness & 12 & 12 \\
\hline Infection & 8 & 8 \\
\hline Nil & 80 & 80 \\
\hline Total & 100 & 100 \\
\hline
\end{tabular}

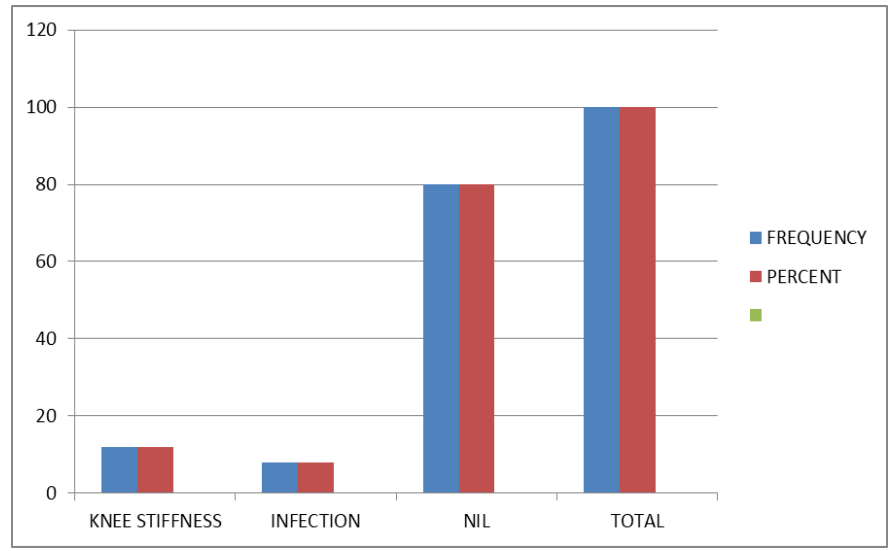

Fig 2

\section{Discussion}

Tibial fractures are more common in males. This is most probably due to most outdoor works and heavier labor undertaken by males as compared to females in the Indian set up. Carried out by males in India. The goal of operative treatment is to obtain anatomical alignment of the joint surface while providing enough stability to allow early motion. This should be accomplished using techniques that minimize osseous and soft tissue devascularization in the hopes of decreasing the complications resulting from treatment. For years now, IMLN had an advantage over other methods because of its early weight bearing and union rate, lesser incidence of infections. In our study, most common cause for these fractures was RTA followed by fall and sports injury, especially football. Our results were comparable to other studies. The common site of tibial fractures in our study was tibial diaphysis in a rate of $(62.5 \%)$ and the right tibia is the common(70\%) which is comparable with a study of Howard M. By the using of johner and wruh's criteria for measurement of the final functional outcomes of both groups we achieved excellent results.

\section{Summary}

2 years study, of 100 cases, 50 were closed fractures \& 50 were open fractures. $20-40$ years constituted $70 \%$ of the study, indicating that active members were commonly involved in the fractures of the tibia. RTA, accidents were the prime cause of tibial fracture, almost $65 \%$ plus of the fractures involved. Dominant side that is right in many patients was commonly involved.

At 16 weeks $45 \%$ of open \& $65 \%$ of closed fractures were almost healed.

\section{Conclusion}

After detailed evaluation, we conclude the following Closed tibial shaft fractures had better \& early union rates at an average of 20 weeks compared to open tibial shaft fractures treated with intramedullary interlocking nailing at an average of 26weeks on both clinical \& radiological basis which was followed up for 6 , 
months.

There was not much difference between Rom at knee \& ankle treated with IMILN in both the groups.

Extensor lag \& ankle stiffness were found in a total of 19 cases, rest all cases returned to their full knee ROM, by 4months.

Higher complications rates were found, to be associated with open injuries, anterior knee pain, infections, etc.

\section{References}

1. Altpeter T, Luckhardt K, Lewis JN et al. Expanded surgical time out: a key to real - time data collection and quality improvement. J Am Coll Surg. 2007; 204:527-532.

2. Batta V, Dwyer AJ, Gulati A, Prakash J, Mam MK, John B. No difference in the long term final functional outcome after nailing or cast bracing of high energy displaced tibial shaft fractures.J Trauma Management Outcomes. 2012; 6:5.

3. Bhandari M, Tornetta P III, Sprague S et al. Predictors of reoperation following Operative management of fractures of the tibial shaft. J Orthop Trauma. 2003; 17(5):353-361.

4. Egol AK, Koval KJ, Zuckerman DJ. Lower extremity fractures and dislocations. ${ }^{[1]} \mathrm{In}$ : Egol AK, Koval KJ, Zuckerman DJ editors. Handbook of fractures. 4ed. Philadelphia: Lippincott Williams \& Wilkins; Wolters Kluwer health, 2010, 464-75.

5. Kwok CS, Crossman PT, Loizou CL. Plate versus nail for distal tibial fractures: a ${ }^{[19]}$ systematic review and metaanalysis. J Orthop Trauma. 2014; 28(9):542-48.

6. Altpeter T, Luckhardt K, Lewis JN et al. Expanded surgical time out: a key to real - time data collection and quality improvement. J Am Coll Surg. 2007; 204:527-532.

7. Niedzwiedzki L. Use of reamed locked intramedullary nailing in the treatment of aseptic Diaphyseal tibial non union. Orthopedic Traumatology Rehabilitation. 2007; 9:384-96.

8. Bishop JA, Dikos GD, Mickelson D, Barei DP. Open reduction and intramedullary nail fixation of closed tibial fractures. Orthopedics. 2012c; 35(11):1631-4.

9. Nascimento OR, Cemin FS, de Morais M, Barroco RS, Fujiki EN, Milani C. Assessment of quality of life in patients with tibia fractures. Acta Orthopedic Bras. 2009; 17:211-4.

10. Trafton PG. Tibial shaft fractures. In: Browner BD, Jupiter JB, Levine AM, Trafton PG, Krettek C, eds. Skeletal Trauma: Basic Science, Management, and Reconstruction. Philadelphia, PA: Saunders. 2009; 2:2319-2451. 